\title{
Patterns of health care for children with asthma: A qualitative study
}

\author{
Rao C. ${ }^{1}$, Ramakrishnan K.G. ${ }^{2}$, Somashekar A. R. ${ }^{3}$ \\ ${ }^{1}$ Dr. Chandrika Rao, Professor, ${ }^{2}$ Dr. Ramakrishnan K.G, MBBS Intern, ${ }^{3}$ Dr. Somashekar. A.R, Professor of \\ Pediatrics, all authors are attached with Department of Pediatrics, Ramaiah Medical College and Hospitals, MSR \\ Nagar, MSRIT Post, Bangalore - 560054, India
}

Address for correspondence: Dr. Ramakrishnan K.G, Email: ramakrishnankg.94@gmail.com

\begin{abstract}
Background: Many children across the world, struggle with asthma, especially when the condition worsens due to lack of adherence to treatment strategies, the reason for which however may not be completely understood. Hence the objective of the study is to explore the perceptions of caregivers and patients about pediatric asthma and its control to trace possible factors that lead to poor adherence to asthma control. Methods: A qualitative study using conversational style interview for a group of 8 children and their guardians was conducted .In the discussion pre set questions were put forward to explore the perceptions of care givers and patients regarding asthma control management. The discussion was recorded with consent and later transcribed, coded and analyzed. Results: The focus group discussion revealed that patient compliance is not perfectly maintained due to various factors. Patients have mixed responses to the restrictions ranging from co-operative to rebellious behavior. Large amount of anxiety exists among the parents with regards to the disease exacerbation and long course of treatment. Frequent hospital visits have been perceived to be cumbersome by them and they perceive a need for the use of such questionnaires as a home based asthma control monitoring system. Conclusion: The focus group discussion reveals that proper counseling system and home based asthma control monitoring system need to be put into place to offer all round asthma control. Also use of questionnaires at home on a regular basis will reduce the number of hospital visits saving time and cost.
\end{abstract}

Key words: Asthma control, Focus group, Pediatric asthma, Qualitative study

\section{Introduction}

The World health organization (WHO) recognizes asthma as a major health problem that affects around 300 million individuals of all ages, ethnic groups and countries. The estimated mean prevalence for the Indian pediatric population is 7.24 (SD 5.42), with urban and male predominance [1]. Compared with adults, children had higher rates for asthma primary care and emergency department visits [2].

Low adherence to inhaled medications leads to increased morbidity [3]. Non compliance to treatment occurs even when parents are supervising care. Decisions regarding treatment are often made based on the opinion of the family members, cultural beliefs and the child's tantrums. These

Manuscript received: $05^{\text {th }}$ July 2017

Reviewed: $15^{\text {th }}$ July 2017

Author Corrected: $20^{\text {th }}$ July 2017

Accepted for Publication: $30^{\text {th }}$ July 2017 affect adherence to therapy and can cause poor compliance, one of the most common preventable causes of asthma morbidity which is often overlooked in day to day practice. Since reasons for poor adherence may not be fully understood it is important to understand the perceptions of patients and their caregivers by building a partnership with parents for long term management of asthma.

Focus group discussions are instrumental in bringing out these non quantifiable aspects of patient care. Krueger describes focus group discussions as carefully designed discussion to obtain perceptions on a defined area of interest in a permissive non threatening environment [4]. They have become increasingly popular in health care, especially in the realm of need assessment [5]. It provides a platform for parent/patient - physician interaction on a 
human level. It is often more effective in drawing parents into discussion than one to one interviews. Furthermore, researchers can look beyond numbers and learn the meaning behind facts. Management of illnesses can be revolutionized when the perceptions of the patients and care givers are kept in mind while providing treatment. It also provides a platform to recognize myths among patients and to instill and educate facts. There by aiding well rounded management of the illness.

This study design hence will be suitable for exploring various factors affecting asthma control.

The objectives of the study is to understand the quality of life of children with asthma, to explore the perceptions of caregivers and patients about asthma and its control and to trace possible factors that lead to poor adherence to asthma control.

\section{Materials and Method}

It was a qualitative study. The sample consisted of children of the age group of 4-12 years visiting M.S Ramaiah hospital for treatment and their care givers. The inclusion criteria included all children between 4-12 years of age diagnosed with asthma for at least 6 months. Children newly diagnosed with asthma, or children with co existing co morbidities were excluded. Ethical clearance was given by the institutional scientific committee. Informed consent was taken from the parents for the interrogation, discussion and the recording of the discussion.

A focused group discussion for a group of 8 children and their guardians was conducted. In the discussion pre set questions were put forward to assess day to day problems of a patient, myths regarding asthma, the difficulties in patient compliance to asthma control management and the need for a more comprehensive home based asthma control system. The discussion was continued till saturation- i.e when additional conversation added nothing further to the subject. This was later transcribed verbatim. A check list was devised to grade the discussion. All transcripts were systematically analyzed. The open codes were applied to the meaning and organized into categories and themes.

\section{Result}

A focused group discussion was conducted for a group of 8 patients and their parents. The patients were known cases of Asthma from a period of six months to up to seven years.

\section{Knowledge about the disease}

"What is asthma?"

When asked about what asthma is to patients and their care givers, they couldn't explain the actual pathology behind asthma i.e broncho constriction but rather expressed the symptoms they associated with the disease. The general symptoms the group complained of were nasal itching, cough, breathlessness and wheezing.

"When does it increase?"

When asked for precipitating factors or aggravating factors; one of the patients complained that consumption of chocolates was the cause, while most others complained about consumption of fruits and oily food substances. One patient stated that the problem started on discontinuation of breast feeding.

"Which season do these problems become worse in?"

Questions directed to seasonal variation brought about a response that asthma symptoms are increased / present only during winter and the same was agreed by all. They discussed the improvement in warm climate.

\section{Personal preventive measures}

"What do you do to prevent asthma attack?"

The next question asked was regarding the day to day personal precaution measures for which patients gave a wide array of answers. One patient asserted on the fact that diet restriction is the most important measure, which ranges from restriction of consumption of chocolates, non-vegetarian food substances or oily food to prevention of food consumption from bakeries and other eateries. Another patient stressed on the fact that 'only hot water' should be consumed. Steam inhalation and gargling is the strategy during cold winter. Use of warm clothes is given a lot of importance by the patients and some patients also felt that yoga and pranayama or evening walks strengthen the lungs.

\section{Patient compliance to preventive measures}

"Do you face difficulties in making your children adhere to treatment and prevention strategies?" 
The next question was on patient compliance to medication which brought out multiple responses from the care givers of the patients. The parent of two asthmatic children stated that the older child listen to us and are co-operative to all the restrictions but the younger one as he has seen the experience of his brother follows the instruction but is not very co-operative: The care giver also said that at young age the patients are more compliant to the restrictions and precautionary measures but as they grew older they compliance reduces and extra pressure needs to be added. As stated by her "He used to wear warm clothes voluntarily in child hood but now since he is in high school he feels awkward and refuses to wear warm clothing".

Another parent stated "how long will children listen to us and follow a restrictive life? They reach a breaking point". On the other hand one care giver stated this with regards to her daughter "she is very mature and follows restrictions on her own but the temptation to eat outside food creeps in and she gives in to the temptation and buys food from outside when she is not supervised". The care giver of another child said that peer pressure makes the child non-compliant and makes her attend social gatherings where she doesn't follow the diet restriction. A patient's resistance to the restrictions is so severe in one case, where as stated by the patient, "the patient hits her head on the floor in grief that she is not able to lead a life like others and eat what every other children eat". The care givers also expressed the difference in thought among the parents of a child with respect to the restrictions. As stated by one patient "if I restrict her from eating something her father secretly gives her the same and she lands up with symptoms". Another patient expressed that the father of the child is against these restrictions because he wants his only child to enjoy his childhood. One of the care givers also complained about non cooperative neighbors who increase dust and smoke, precipitating asthma symptoms in the patient.

\section{Perspectives of the care givers regarding medication:}

"How important are medications?"

The question that followed was regarding the patients' and parents' perspective of importance of medication. The overall opinion of parents is that medication is inevitable. But one parent feels that the medication doesn't reach optimal use because of poor environment and pollution. Another parent is frightened and depressed that during attacks even medications cannot control the asthma symptoms. However, in this part of discussion a parent put forward a question rather a misconception that whether the use of an inhaler without a spacer worsens the condition of patient.

There was a common belief amongst the parents that following preventive measures and taking medications in childhood would cure the disease and prevent it from continuing to adulthood.

"Do you use medicines from alternate systems of health care?"

The next question put forward was the use of alternate forms of medicine. All parents agreed that there is excessive pressure from family and friends to start the child on other forms of medication but none of the parents venture into these medications they feel "child's health is most important". One caregiver said "I put my child on Ayurvedic treatment because of family pressure but shifted over to English medicine (Allopathy) as it offers quick relief".

\section{Restrictions in day to day life}

"How is your child's day to day life affected by asthma?"

The next question was directed to bring out feelings of patients and parents with respect to restriction of day to day life due to the disease and restriction to extracurricular activities. All parents agree that their children's life has been restricted to a large extent. One parent says 'he is very interested in sports but what to do, he can't take part in anything'. Another parent complains that her son has been prohibited from doing any extracurricular activities by the school as the school has been directed to do so by the father of the child. This makes the child very depressed. Another patients' care giver stated 'the aunt of the patient had same problem which got cured by the time she reached adolescence. So I think restrictions are good as she might get cured like her aunt.'

The question that followed addressed the parents' / care givers' reaction to night symptoms. One parent started to cry, she says it is so frequent and is very scary sometime. Another parent who lives far away from the hospital says I am helpless when this occurs. I have to wait till next morning, I feel very 
sad that with so many medications these things recur'.

\section{Burden of continuous asthma control surveillance}

"What do you feel about the need to make repeated hospital visits?"

The most distressing part of asthma management is that it can be only controlled and not cured. So the next question was phrased to bring out the reactions of parents to this continuous need to make frequent hospital visits. The response from one parent was that "yes, she has to miss school as check-up time clashes with school hours, as a result of which lot of work piles up and there is extra stress on her but she has to cope with it. There is no other go".

Two questionnaires the C-ACT and ATAQ were introduced and its utility was explained to the group. The idea of using them as a home based asthma control evaluation system was introduced. The patients were told how it works and how warning signs were to be looked for. At the end of this, the patients were asked whether they would trust such questionnaires and use it as a method for evaluation, rather than making frequent hospital visits, unless the need to visit hospital arises. In response all patients nod their heads in agreement and some parents said such a system is very efficacious as it would save them the trouble of hospital visits and they assert that it should be put to practice.

The focus group was concluded by answering questions put forward by the patients and addressing the myths that arose.

Analysis of the focus group discussion lead to four dominant themes and are summarized as follows.

The factors leading to poor adherence to treatment and exacerbation prevention strategies are:

- Difficult to convince children and control them as they grow older and symptoms begin to resolve.

- Peer pressure causes poor compliance to treatment and asthma exacerbation prevention strategies.

- Tantrums are common among younger children while leading a restricted life.

- Conflict between family members or parents resulting from different perceptions of preventive measures.
- Family pressure to discontinue allopathic medications.

- Pampering by the elderly of the family leads to straying from these preventive measures.

- Poor environment around home as a result of non co-operative neighbors.

- Lack of clear knowledge about the disease.

The factors favoring good adherence to treatment and exacerbation prevention strategies are:

- Fair amount knowledge regarding symptoms and seasonal variations amongst caregivers, hence helpful to monitor and detect poor control and exacerbations

- Good appreciation of the importance and requirement of medication.

- Good adherence to a single system of health care.

- Good knowledge regarding personal preventive measures

- Examples of asthmatics with good control in and around home to aid as an inspiration to adhere to the treatment and exacerbation prevention strategies.

- Positive attitude regarding health, as a parent says "Child's health is most important".

The Effects of asthma in day to day life :

- Living a restricted childhood leads to frustration in children.

- Exacerbation and regular visits to the clinics causes loss of school time leading to backlog in academics.

- Participation in sports and other extra cultural activities are often limited.

- Parents lose work time because of the need for regular hospital visits

- Fear and helplessness among parents during exacerbation and due to the (large) distance from health care facility.

The problems parents face in the process of achieving asthma control:

- Difficulty in making children compliant to treatment, especially older, who are under constant peer pressure.

- Frustration in children manifesting as tantrums are hard to control and difficult to handle.

- Parents feel a loss of control in social gatherings, hence giving room for straying from the asthma control strategies.

- Family pressure, especially to try treatment from alternate systems of medicine like ayurveda. 
- Parents feel helplessness and immense fear during exacerbation in the night time.

- Parents have a difficult time bridging the distance between home and the health care facility.

- Parents raised a concern that if spacers aren't used for inhaled medication the problem will actually worsen.

\section{Discussion}

Parents play a pivotal role in the management of their child's asthma. They make the primary decision on medical advice given for their child's condition. This parental decision is based on their own perceptions about illness and medication [6]. Focus group discussions bring out the wider understanding at community level, along with their personal understanding. Hence this qualitative study was aimed at exploring these varied perceptions through focus group discussion which possibly could be a cause for lack of adherence to treatment.

Through the study it was discovered that the knowledge of parents regarding the disease was limited to the symptoms they observed and the underlying cause was largely unknown to them, which could have a bearing on how they approach long term treatment. This is similar to the findings in the study conducted by Rachel $\mathrm{C}$ et al, where mothers from different ethnic backgrounds described asthma primarily in terms of the symptoms they saw [7]. However in the study done by Wern $\mathrm{F}$ et al, asthma was thought to be infectious spreading from one person to another, this was not observed in the current study [8]. Furthermore parents express fear, anxiety and helplessness during acute attacks. This is a common observation as seen in many previous studies [7- 10]. In the current study it was also observed that the fear is worsened due to the distance of health care centers from home, especially during acute exacerbation. Another unique observation in this study is the discord between the father and mother regarding the disease and its management, hampering optimal asthma control. This could be attributed to the lack of knowledge and brings out the need to counsel and educate both parents about the disease.

Another common concern among parents is the effect of peer pressure and its effects on compliance to treatment and adherence to measures preventing acute attacks. Parents feel that once their children grow older they express their preferences. This is often worsened in social gatherings and trips and is viewed as an embarrassment by the child. This is an observation unique to the study. Further they express that some children become frustrated and throw tantrums when made to adhere to treatment strategies. This frustration is further worsened when they feel restricted due to the disease not enabling them to enjoy their favorite food or take part in sports activities making them non compliant in the long run as has also been noted in the study conducted by $\mathrm{M}$ Jhonson et al [10]. Hence children should be counseled and educated regarding the importance of compliance. They should be trained to cope with limitations brought by asthma which would possibly reduce when asthma is well controlled.

Parents feel adherence to strict dietary restrictions is equally important in management of asthma which is similar to the observation in the study conducted by Cane et al [7], [8][11]. However, the extent of its benefit has to be verified. Parents also recognize that the surrounding environmental has a bearing on their child's health as mentioned in other studies [12].

In the adult population, patients with asthma took into consideration the cost of therapy, which affected adherence to asthma control therapy as demonstrated by the study conducted by Dianne P et al [13]. This factor however was not seen in the pediatric population as parents had high regard and concern for their children's health.

Overall parents show a keen interest in their child's health and value it deeply. As mentioned by a parent "child's health is most important". This forms a good soil for re enforcing the importance of adherence and close follow up.

As demonstrated by the study, focus group discussions are effective in bringing forwards perceptions and inner most thoughts of parents and caregivers which are otherwise often missed out on in routine clinical care. Parents are able to communicate their major concerns well and their emotions are brought out through these focus groups. Furthermore, as demonstrated in the present study and the study conducted by William B et al, it provides an opportunity for parents to view the perceptions of others and sympathize with them, 
which can be an enriching experience in itself [14]. However such discussions are prone to be steered by dominant members as was observed in this discussion too. Not only do these studies enable patient physician relationships they also work as an effective research tool. Large amount of data can be collected over a short period of time and unique aspects of patient care can be touched upon [15]. A careful selection of participants and a tactful structuring of discussion can make it a resourceful way of exploring the various qualitative aspects of diseases and their management.

The strengths of the study are that parents of these young asthmatics showed good enthusiasm to take part in the discussion. One positive feature was the interaction between parents regarding their children's problems. Parents listened intently while other parents spoke and often added to their points and sympathized with them. This interaction continued even after the focus group was concluded. This feature of focus groups is as described in a study conducted by Morgan DL et al [16].

The limitations were that the study design did not pay attention to selecting groups based on socialeconomic, demographic and linguistic factors. This would have enabled smoother interactions and an insight to problems specific to different groups of the society.

India being a culturally diverse country posed its own challenges to the study. Since there was linguistic diversity in the group, not all of them were able to optimally communicate their perceptions and concerns in the chosen language of discussion with the doctors and each other.

India with the concept of joint families still widely prevalent opens us to the possibilities of the effect of compliance of other family members. While it did provide examples of asthmatics who have achieved control to live up to, it also brought with it the lack of compliance induced by the pampering of the asthmatics by elderly and their view of asthma management and its effects on childhood. In such situations since parents loose absolute control and counseling of other family members becomes essential.

Another problem unique to India is the prevalence of a range of alternative systems of medicine. This not only confuses parents but also becomes a source of pressure in deciding the right method of treatment accentuated by family members who urge parents to try alternative medicines.

\section{Conclusion}

The qualitative analysis reveals that asthma care requires an overall management and close follow up of the patient in addition to medications and precautionary measures .Detailed counseling to the patients and caregivers about various aspects of the disease and the need for following precautionary measures is absolutely necessary. Parents can be taught basic quick relief strategies or treatment to reduce anxiety during attacks. Also a home based monitoring system should be established such that, patients once off medication after achieving desirable asthma control can monitor it on a regular basis and visit hospitals only when the questionnaire indicates uncontrolled asthma. This spares a lot of time and resources for the patient and the doctor and reduces anxiety among the care givers.

Focus group discussion proves to be an useful tool for qualitative data collection and also acts as a temporary support group for the parents.

Acknowledgements- The institution and its scientific committee have played a fundamental role in providing us the opportunity and encouragement to perform this research work. We thank Dr Roopakala, Secretary of student research committee for scientific advice through the process. We extend a heart filled gratitude to Dr. Karunakar, head of Department of Pediatrics for the constant support and encouragement. A special thanks to Mrs Radhika, statistician for technical support on statistics. No acknowledgement is complete without thanking the patients and caregivers who actively took part in the research work.

Funding: Nil, Conflict of interest: None initiated, Perission from IRB: Yes

\section{References}

1. Pal R, Dahal S, Pal S. Prevalence of bronchial asthma in Indian children. Indian J Community Med. 2009 Oct;34(4):310-6. doi: 10.4103/09700218.58389 .

2. Akinbami LJ, Moorman JE, Bailey C, Zahran HS, King M, Johnson CA, Liu X. Trends in asthma 
prevalence, health care use, and mortality in the United States, 2001-2010. NCHS Data Brief. 2012 May;(94):1-8.

3. Rachel A E. Poor adherence to anti-inflammatory Medication in asthma. Disease management and health outcomes. April 2006,14(4) 223-233.

4. Krueger RA. Focus groups. A practical guide for applied research and ed. Thousand oaks CA:Sage publications, Inc;1994; 2(10):63-68.

5. Mansell I, Bennett G, Northway R, Mead D, Moseley L. The learning curve: the advantages and disadvantages in the use of focus groups as a method of data collection. Nurse Res. 2004;11(4):79-88.

6. T. Klok,P.L.P. Brand,H. Bomhof-Roordink,E.J. Duiverman,A.A. Kaptein,Parental illness perceptions and medication perceptions in childhood asthma, a focus group study,Acta Pædiatrica 2011;100:248-252.

7. Rachel C, Caroline $\mathrm{P}$ and $\mathrm{S}$ McKenzie. Understanding childhood asthma in focus groups: perspectives from mothers of different ethnic backgrounds BMC Family Practice 2001, 2:4.

8. Wern F,Ngiap Chuan T,.The influence of caregivers' knowledge and understanding of asthma aetiology on domiciliary management of children with asthma. Singapore Med J 2014; 55(3): 132136.

9. Rudell K, Hareendran A, Bonner N, Arbuckle R, Burbridge C, Abetz L. Patients' experience of asthma control and clinical guidelines: perspectives from a qualitative study. Respir Med. 2012 Jun;106(6):909-11. doi: 10.1016/j.rmed.2011.08.024. Epub 2012 Feb 22.

10. M. Jonsson, A-C. Egmar, E. Hallner, I. Kull, Experiences of living with asthma - a focus group study with adolescents and parents of children with asthma J Asthma, 2014; 51(2): 185-192.

11. Hijazi N, Abalkhail B, Seaton A. Diet and childhood asthma in a society in transition: a study in urban and rural Saudi Arabia. Thorax. 2000 Sep;55(9):775-9.

12. Stone V. Environmental air pollution. Am J Respir Crit Care Med. 2000 Aug;162(2 Pt 2):S44-7.

13. Goeman DP, Aroni RA, Stewart K, Sawyer SM, Thien FC, Abramson MJ, Douglass JA. Patients' views of the burden of asthma: a qualitative study. Med J Aust. 2002 Sep 16;177(6):295-9.

14. William B,Evaluating the Efficacy of Focus Group Discussion (FGD) in Qualitative Social Research ,International Journal of Business and Social Science , April 2012;3(7):54-57.

15. Caroline MH, Ellis H,.The use of focus groups in paediatric health research, journal of paediatric psychology 2002; 27(1): 47-57.

16. Morgan DL. Reconsidering the role of interaction in analyzing and reporting focus groups. Qual Health Res. 2010 May;20(5):718-22. doi: $10.1177 / 1049732310364627$.

\section{How to cite this article?}

Patterns of health care for children with asthma: A qualitative study. Rao C., Ramakrishnan K.G., Somashekar A. R. J PediatrRes.2017;4(07):446-452.doi:10.17511/ijpr.2017.i07.03. 